\title{
ANALISIS PERAN FOREIGN DIRECT INVESTMENT (FDI) SEBAGAI PEMICU KEBERHASILAN KOMERSIALISASI INOVASI TEKNOLOGI TINGGI DI NEGARA-NEGARA ASIA
}

\author{
ANALYSIS OF THE ROLE OF FOREIGN DIRECT INVESTMENT (FDI) \\ AS A TRIGGER OF SUCCESSFUL COMMERCIALIZATION \\ OF HIGH TECHNOLOGY INNOVATION IN ASIAN COUNTRIES
}

\author{
Sarli Rahman', Andi $\mathbf{O h}^{2}$ \\ Sekolah Tinggi Ilmu Ekonomi Pelita Indonesia, Indonesia ${ }^{1,2}$ \\ sarli.rahman@lecturer.pelitaindonesia.ac.id ${ }^{1}$
}

\begin{abstract}
Innovation activities are important things that must be done by a country, but unfortunately not all countries can do it, especially in the high-tech industry, because it requires a very large investment. This study aimed to analyze the role of FDI as a trigger for the successful commercialization of high technology innovations in Asian countries. Innovation is something that must be done by a country in order to compete in the international market, but most Asian countries have limitations in terms of capital, technology and skills to do it. One of solution that can be done is to attract as much investment from abroad through foreign direct investment (FDI). Of the 49 countries in Asia according to id.wikipedia.org, 21 countries countries have been selected as research samples. From the result of structual equation modeling (SEM) analysis founds that FDI was not able to trigger and boost innovation activities of countries in Asia, as measured through spending on $R \& D$ activities, number of patent applications, and research journals published internationally. The role of FDI in Asian countries is more to assist these countries in producing results from innovation activities.
\end{abstract}

Keywords: R\&D Expenditures, Number of Patent Applications, Number of journal publications, FDI, High-tech export

\begin{abstract}
ABSTRAK
Aktivitas inovasi merupakan hal penting yang harus dilakukan oleh sebuah negara, namun sayangnya tidak semua negara dapat melakukannya, apalagi di industri teknologi tinggi, karena memerlukan investasi yang sangat besar. Penelitian ini dilakukan untuk menganalisis peran FDI sebagai pemicu keberhasilan komersialisasi inovasi teknologi tinggi di negara-negara Asia. Di satu sisi inovasi merupakan sesuatu yang penting untuk dilakukan oleh sebuah negara agar bisa bersaing di pasar internasional, namun di sisi lain negara-negara di Asia sebagaian besar memiliki keterbatasan dalan hal modal, teknologi dan skill. Salah satu solusi yang dapat dilakukan adalah menarik sebanyak mungkin investasi dari luar negeri melalui foreign direct investment (FDI). Dari 49 negara yang berada di Asia menurut id.wikipedia.org, terpilihlah 21 negara yang akan menjadi sampel penelitian. Dari analisis structual equation modeling (SEM) yang
\end{abstract}


dilakukan didapatkan bahwa FDI tidak mampu memicu dan mendongkrak aktivitas inovasi negara-negara di Asia, yang diukur melalui belanja untuk aktivitas $R \& D$, jumlah aplikasi paten, serta jurnal-jurnal penelitian yang dipublikasikan secara internasional. Peran FDI di negara-ngera Asia lebih kepada untuk membantu negara-negara tersebut dalam memproduksi hasil-hasil dari aktivitas inovasi.

Kata Kunci: Belanja R\&D, Jumlah Aplikasi Paten, Jumlah Jurnal Publikasi, FDI, Ekspor Produk Berteknologi Tinggi

\section{PENDAHULUAN}

Saat ini negara-negara di Asia telah mengalihkan arah perdagangannya kepada produk-produk berteknologi tinggi. Hal ini tercermin dari nilai total ekspor produk-produk berteknologi tinggi (high-tech) negara-negara Asia yang mengalami tren kenaikan dari tahun 2000 yang hanya berkontribusi sebesar $34,84 \%$ dari total ekspor produk-produk berteknologi tinggi di dunia. menjadi $51,70 \%$ pada tahun 2016. Tentu saja pencapaian ini tidak terlepas dari keberhasilan negara-negara di Asia dalam melakukan berbagai inovasi di bidang teknologi dan mengkomersialisasikannya. Dipelopori oleh China, Japan, Korea dan Singapura, negara-negara di Asia telah berinvestasi sangat besar pada aktivits Research \& Development (R\&D). Belanja R\&D negara-negara seperti Korea, Cina dan Malaysia mengalami kenaikan lebih dari dua kali lipat pada tahun 2016 jika dibandingkan yang mereka keluarkan di tahun 2000. Sementara itu Jepang, selalu menjaga belanja R\&D mereka untuk tetap di atas $2,5 \%$ dari produk domestik bruto (PDB) nasional mereka.

Data-data

tersebut mengidentifikasikan bahwa terdapat korelasi dan hubungan yang positif antara inovasi yang dilakukan oleh negara-negara di Asia dengan peningkatan nilai ekspor produk-produk berteknologi tinggi, yang mana hubungan positif antara inovasi dan nilai ekspor produk-produk berteknologi tinggi telah dibuktikan oleh peneliti-peneliti sebelumnya (Sandu \& Ciocanel, 2014; Kabaklarli et al, 2017, 2018).

Aktivitas inovasi merupakan hal penting yang harus dilakukan oleh sebuah negara, namun sayangnya tidak semua negara dapat melakukannya, apalagi di industri teknologi tinggi, karena memerlukan investasi yang sangat besar (Ekananda \& Parlinggoman, 2017). Sebagai contoh lihatlah bagaimana China telah membelanjakan rata-rata 87 milyar dolar Amerika per tahunnya untuk aktivitas R\&D (Wu, 2010), sehingga mereka bisa mencapai posisinya seperti saat ini. Dengan jumlah investasi yang sebesar itu, tentu akan menyulitkan negara-negara miskin yang berada di Asia untuk melakukannya. Salah satu solusi yang dapat dilakukan adalah menarik sebanyak mungkin investasi dari luar negeri melalui foreign direct investment (FDI). FDI juga yang telah membuat China menjadi raksasa industi teknologi tinggi saat ini ( $\mathrm{Li}$ et al, 2018). Selain dapat menjadi solusi dalam persoalan keuangan, FDI juga dapat menjadi solusi bagi pemenuhan tekonologi, keahlian \& keterampilan serta manajemen modern (Khachoo \& Sharna, 2017).

Meskipun banyak ahli dan peneliti bersepakat tentang pentingnya FDI dalam aktivitas inovasi sebuah negara, namun masih terdapat kebingungan teori terkait dimana peran FDI dalam mempengaruhi aktivitas inovasi di 
sebuah negara. Apakah FDI berperan sebagai pemicu inovasi (Khachoo \& Sharma 2017; Ghazal \& Zulkhibri 2014; Chen \& Chen 2009), atau FDI berberan sebagai faktor yang dipengaruhi oleh inovasi (Khachoo \& Sharma 2017; Ghazal \& Zulkhibri 2014; Chen \& Chen 2009), atau FDI berperan sebagai moderator yang dapat meningkatkan peluang keberhasilan inovasi (Ismail, 2013; Rahman et al, 2019). Untuk itu perlu dilakukan penelitian lanjutan untuk menetukan bagaimana peran FDI sebenarnya terkait dengan aktivitas inovasi di sebuah negara, yang mana pada penelitian ini berfokus untuk menganalisis peran FDI sebagai faktor pemicu aktivitas inovasi di negara-negara Asia.

Tidak bisa dipungkiri, untuk melakukan sebuah inovasi diperlukan sumber daya yang besar, terutama dalam hal modal, yang mana modal tersebut akan digunakan dalam aktivasi penelitian dan pengembangan, mempublikasikan hasil penelitian atau mematenkannya. Untuk negara-negara maju di benua Amerika dan Eropa, tentu saja modal bukanlah menjadi persoalan yang dapat menghambat mereka untuk melakukan aktivitas inovasi, namun tidak demikian dengan negara-negara di Asia. Sebagian besar negara-negara di Asia masih tergolong sebagai negara ketiga dan berkembang dengan keterbatasan modal yang mereka miliki. Tentu saja hal tersebut dapat menghambat negara-negara di Asia untuk melakukan aktivitas inovasi. Agar negara-negara di Asia dapat melakukan inovasi, tentunya mereka mebutuhkan investasi dari pihak asing dalam bentuk foreign direct investment (FDI). Penelitian-penelitian terdahulu telah membuktikan bahwa FDI berpengaruh langsung secara positif terhadap pengembangan aktivitas inovasi yang diukur melalui aktivitas
R\&D, aplikasi paten dan publikasi jurnal penelitian (Gervais, 2009; Chen \& Chen, 2009; Leman \& Ismet Gocer, 2015) maupun terhadap nilai ekspor sebuah negara (Weishi et al, 2008 ; Zhang \& Kevin, 2006).

Sementara itu terkait dengan hubungan aktivitas inovasi (R\&D, aplikasi paten dan publikasi jurnal penelitian) dengan nilai ekspor produk berteknologi tinggi telah diteliti oleh Braunerhjelm (2008) yang menemukan bahwa peningkatan nilai ekspor produk berteknologi tinggi di sebuah negara mengikuti peningkatan belanja $R \& D$ negara tersebut. Begitupun halnya dengan paten, dimana jika terjadi penguatan paten di sebuah negara dapat meningkatkan nilai ekspor produk berteknologi tinggi (Olena, 2010), bahkan dampaknya lebih besar daripada nilai ekspor produk biasa (Chih-Hai \& Yi-Ju, 2009).

Satu peran lainnya dari FDI yang kurang mendapat perhatian dari penelitian terdahulu adalah perannya sebagai variabel moderasi yang dapat memperbesar peluang keberhasilan aktivitas inovasi sebuah negara. Setidaknya ada dua penelitian yang dapat ditemui yang menguji peran FDI sebagai variabel moderasi, yaitu Ismail (2013) dan Rahman et al (2019) yang menemukan bahwa FDI memiliki pengaruh moderasi yang dapat memperbesar keberhasilan inovasi dalam meningkatkan nilai ekspor produk berteknologi tinggi.

\section{METODE PENELITIAN Populasi dan Sampel}

Pada penelitian ini yang menjadi populasinya adalah 49 negara Asia yang berdaulat menurut id.wikipedia.org. Sementara itu sampel penelitian dipilih dengan metode purposive sampling berdasarkan kriteria setiap negara memiliki data belanja $\mathrm{R} \& \mathrm{D}$, jumlah 
aplikasi paten, foreign direct investment net inflows dan nilai ekspor produk berteknologi tinggi selama periode tahun 2002 - 2017, sehingga terpilih sebanyak 21 negara sbagai sampel penelitian, seperti yang tercantum pada tabel berikut:

Tabel 1. Daftar Negara yang Menjadi Sampel Penelitian

\begin{tabular}{cccc}
\hline No. & Negara & No. & Negara \\
\hline 1. & Armenia & 12. & Korea, Rep. \\
\hline 2. & Azerbaijan & 13. & Kyrgyz \\
\hline 3. & China & 14. & Malaysia \\
\hline 4. & Georgia & 15. & Pakistan \\
\hline 5. & Hong Kong & 16. & Philippines \\
\hline 6. & India & 17. & Sri Lanka \\
\hline 7. & Indonesia & 18. & Singapore \\
\hline 8. & Israel & 19. & Thailand \\
\hline 9. & Japan & 20. & Turkey \\
\hline 10. & Jordan & 21. & Vietnam \\
\hline 11. & Kazakhstan & & \\
\hline
\end{tabular}

\section{Defenisi Operasional Variabel Penelitian}

Berikut disajikan defenisi operasional dari beberapa variabel yang digunakan pada penelitian ini, lengkap denan singkatan nama variabel dan sumber datanya:

\section{Tabel 2. Defenisi Operasional} Variabel Penelitian

\begin{tabular}{|c|c|}
\hline Variabel & Defeni \\
\hline $\begin{array}{l}R \& D \text { Expenditures } \\
(\mathrm{RDE})\end{array}$ & $\begin{array}{l}\text { Persentase dari be } \\
\text { terhadap PDB }\end{array}$ \\
\hline $\begin{array}{l}\text { Jumlah Aplikasi Paten } \\
\text { (Log_Patent) }\end{array}$ & $\begin{array}{l}\text { Jumlah aplikasi paten } \\
\text { untuk hak eksklusif }\end{array}$ \\
\hline FDI inflows (FDI) & $\begin{array}{l}\text { Persentase dari FDI } n \\
\text { terhadap PDB }\end{array}$ \\
\hline $\begin{array}{l}\text { Jumlah Jurnal Publikasi } \\
\text { (Log_Journal) }\end{array}$ & $\begin{array}{l}\text { Jumlah jurnal interna } \\
\text { terpublikasi }\end{array}$ \\
\hline $\begin{array}{l}\text { Ekspor Produk } \\
\text { Berteknologi Tinggi } \\
\text { (Log_HTE) }\end{array}$ & $\begin{array}{l}\text { Nilai ekspor produk-1 } \\
\text { berteknologi tinggi }\end{array}$ \\
\hline \multicolumn{2}{|c|}{$\begin{array}{l}\text { Kerangka Konseptual } \\
\text { Pada penelitian ini variabel- } \\
\text { variabel yang digunakan adalah jumlah } \\
\text { publikasi jurnal, jumlah aplikasi patent, } \\
\text { belanja R\&D, foreign direct investment }\end{array}$} \\
\hline
\end{tabular}

net inflows, dan nilai ekspor produk berteknologi tinggi dengan kerangka konseptual sebagai berkut:

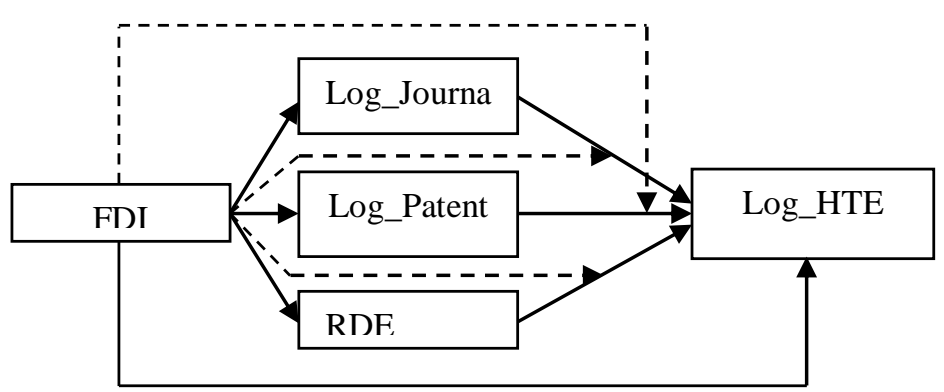

$$
\text { Gambar 1. Kerangka Konseptual }
$$

\section{HASIL DAN PEMBAHASAN}

Pengolahan data dilakukan dengan metode structual equation modeling (SEM) melalui bantuan program SmartPLS versi 3.2.8.

\section{Statistik Deskriptif}

Tabel 3. Statistik Deskriptif Data Variabel Penelitian

\begin{tabular}{llrr}
\hline & N & \multicolumn{1}{c}{ Mean } & Std. Deviation \\
\hline RDE & 336 &, 97372 & 1,20773 \\
\hline FDI & 336 & 6,18320 & 8,96283 \\
\hline Log_HTE & 336 & 9,28196 & 1,48671 \\
\hline Log_Paten & 336 & 2,99237 & 1,10779 \\
\hline Log_Journal & 336 & 3,73493 &, 90140 \\
\hline \multicolumn{2}{c}{ Sumber : Data Olahan $(2019)$} &
\end{tabular}

Sumber : Data Olahan (2019) deskriptif dari data penelitian. Dari tabel penedsedbut diketahui bahwa rata-rata nilai FDI yang didapat atau diterima oleh hegara-negara di Asia adalah sebesar yang $8320 \%$ dari nilai produk domestik bruto (PDB) negaranya, dengan nilai standar deviasi sebesar 8,96283, yang merupakan nilai standar deviasi terbesar dari data-data penelitian yang lainnya. Hal ini menandakan adanya kesenjangan investasi asing yang diterima oleh negara-negara di Asia. 


\section{Pengaruh FDI Terhadap RDE, Log_Patent, Log_Journal \& Log_HTE}

$\quad$ Tabel 4 menyajikan
bootstrapping
menunjukan pengaruh langsung FDI
terhadap $\quad$ RDE, $\quad$ Log_Patent,
Log_Journal \& Log_HTE.

Tabel 4. Hasil Uji Statistik Pengaruh

\begin{tabular}{lcc}
\multicolumn{3}{c}{$\boldsymbol{F D I}$} \\
\hline & $\begin{array}{l}\text { Original } \\
\text { Sample }\end{array}$ & P Values \\
\hline FDI -> Log_HTE & 0,135 & 0,009 \\
\hline FDI -> Log_Journal & $-0,131$ & 0,005 \\
\hline FDI -> Log_Patent & $-0,247$ & 0,000 \\
\hline FDI -> RDE & $-0,128$ & 0,010 \\
\hline Sumber : Data Olahan (2019) &
\end{tabular}

Hasil pengolahan data yang terjadi pada tabel 4 membuktikan bahwa FDI berpengaruh secara signifikan terhadap aktivitas inovasi yang diwakili oleh RDE, Log_Patent dan Log_Journal. Hal ini ditandai dengan semua nilai $\mathrm{P}$ Values $<0,05$.

Namun meskipun demikian, jika ditelaah arah pengaruhnya, maka diketahui bahwa FDI mempengaruhi RDE, Log_Patent dan Log_Journal dalam arah yang negatif. Dengan demikian maka $\mathrm{H} 1, \mathrm{H} 2$ dan $\mathrm{H} 3$ ditolak, yang berarti variabel FDI tidak berpengaruh secara psoitif terhadap RDE, Log_Patent dan Log_Journal, yang artinya dapat disimpulkan bahwa FDI tidak dapat menjadi pemicu dalam hal peningkatan aktivitas research \& development, peningkatan produkproduk terbaru yang dipatenkan, serta peningkatan dalam aktivitas riset, baik oleh perguruan tinggi, pemerintahan maupun pihak swasta.

Sementara itu dari tabel yang sama diketahui bahwa FDI berpengaruh secara signifikan dalam arah yang positif terhadap variabel Log_HTE, yang artinya $\mathrm{H} 4$ diterima. Hal ini mengindikasikan bahwa sebenarnay
FDI lebih berperan kepada penyediaan modal dan paket investasi yang terkandung didalamnya seperti teknologi, skill, manajemen modern, proses baru, dan lain sebagainya (Khachoo \& Sharna, 2017) dalam hal untuk memproduksi hasil-hasil dari aktivitas inovasi.

\section{Pengaruh RDE, Log_Patent, Log_Journal Terhadap Log_HTE}

Tabel 5 menyajikan hasil bootstrapping SmartPLS yang menunjukan pengaruh langsung $R D E$, Log_Patent \& Log_Journal Terhadap Log_HTE.

Tabel 5. Hasil Uji Statistik Pengaruh RDE, Log_Patent \&Log_Journal

\begin{tabular}{lrr}
\hline & $\begin{array}{l}\text { Original } \\
\text { Sample }\end{array}$ & P Values \\
\hline Log_Journal -> Log_HTE & $-0,070$ & 0,206 \\
\hline Log_Patent -> Log_HTE & $-0,185$ & 0,005 \\
\hline RDE -> Log_HTE & $-0,240$ & 0,001 \\
\hline
\end{tabular}

Sumber : Data Olahan (2019)

Dari tabel 5 diketahui bahwa bahwa Log_Journal tidak berpengaruh secara signifikan terhadap Log_HTE, yang ditandai dengan nilai $P$ Values $>0,05$. Dengan demikian maka H5 ditolak. Hal ini dapat dipahami mengingat jurnal-jurnal penelitian internasional yang dipublikasikan kebanyakan masih bersifat penelitan dasar yang tidak dengan serta merta dapat dijadikan sebuah produk. Selain itu tidak semua jurnal-jurnal penelitian internasional yang dipublikasikan terkait dengan pengembangan produk berteknologi tinggi, namun juga pada bidang kajian ilmu lainnya.

Sementara itu untuk pengaruh Log_Patent dan RDE terhadap Log_HTE diketahui berpengaruh secara signifikan, namun dengan arah yang negatif. Dengan demikian maka H6 dan H7 ditolak. Tentu saja hasil ini mengejutkan, karena secara teori 
seharusnya semakin banyak aktivitas R\&D akan menghasilkan penemuanpenemuan terbaru yang dipatenkan yang nantinya dapat diproduksi menjadi produk-produk teknologi tinggi terbaru, yang dengan sendirinya dapat meningkatkan nilai ekspor produk berteknologi tinggi sebuah negara. Namun hasil berbeda justru di dapat dari penelitian ini.

Hal ini mengindikasikan bahwa tidak semua hasil inovasi dapat dikomersialisasikan dengan sukses (Adams et al, 2006). Salah satu penyebab kenapa negara-negara di Asia tidak dapat mengkomersialisasikan hasil aktivitas inovasinya adalah karne keterbatasan modal, teknologi dan skill yang mereka miliki. Hasil penelitan ini sejalan dengan Mehrara et al (2017), Shukla (2017), Hasanov et al (2015) dan Petrariu (2013), namun bertentangan dengan hasil penelitian Sandu \& Ciocanel (2014) yang menyimpulkan bahwa $R D E$ berpengaruh positif dan signifikan terhadap nilai ekspor produk berteknologi tinggi, serta penelitian Kabaklarli et al (2017), yang menemukan bahwa aplikasi paten berpengaruh positif terhadap nilai ekspor produk berteknologi tinggi.

Pengaruh Moderasi FDI

Tabel 6 menyajikan hasil
bootstrapping SmartPLS yang
menunjukan pengaruh moderasi FDI
yang dapat menguatkan pengaruh
variabel Log_Journal, Log_Patent dan
RDE terhadap HTE.

Tabel 6. Hasil Uji Statistik Pengaruh Moderasi FDI

\begin{tabular}{lcr}
\hline & $\begin{array}{l}\text { Original } \\
\text { Sample }\end{array}$ & P Values \\
\hline Log_Journal-FDI -> Log_HTE & $-0,176$ & 0,008 \\
\hline Log_Patent-FDI -> Log_HTE & 0,031 & 0,650 \\
\hline RDE-FDI -> Log_HTE & 0,116 & 0,161 \\
\hline Sumber : Data Olahan (2019) & &
\end{tabular}

Dari tabel 6 diketahui bahwa bahwa meskipun dengan bantuan FDI, jurnal-jurnal penelitian internasional yang dipublikasikan tidak dapat mempengaruhi nilai ekspor produk berteknologi tinggi secara positif.

Sementara itu untuk pengaruh Log_Patent dan RDE terhadap Log_HTE, dengan bantuan FDI dapat mengubah arah pengaruh yang semula negatif menjadi positif. Tentu saja ini menguatkan pernyataan sebelumnya yang menyatakan negara-negara di Asia memiliki keterbatasan modal, teknologi dan skill yang mengakibatkan mereka tidak mampu untuk mentranformasi hasil $R \& D$ dan paten mereka menjadi produk-produk berteknologi tinggi terbaru dan memproduksinya. Namun dengan paket investasi asing dalam bentuk FDI setidaknya mereka dapat membantu negara-negara di Asia meningkatkan nilai ekspor produk berteknologi tinggi mereka, meskipun tidak signifikan secara statistik. Dengan demikian secara statistik dapat dinyatakan bahwa $\mathrm{H} 8, \mathrm{H} 9$ dan $\mathrm{H} 10$ ditolak.

\section{PENUTUP \\ Kesimpulan}

Penelitian ini dilakukan untuk menganalisis bagaimana peran dari FDI dalam memicu aktivitas inovasi negaranegara di Asia serta keberhasilan mereka dalam melakukan komersialisasi hasil aktivitas inovasi tersebut. Salah satu alasan kenapa paket investasi dalam bentuk FDI diperlukan oleh negara-negara di Asia karna sebagai besar negara-negara di Asia memiliki keterbatasan modal, teknologi dan skill sehingga mereka kesulitan untuk melakukan inovasi, begitupun untuk merealisasikannya dalam bentuk produk kemudian memproduksinya dan memasarkannya. 
Dari analisis yang dilakukan diketahui bahwa investasi Asing dalam bentuk FDI tidak mampu memicu dan mendongkrak aktivitas inovasi negaranegara di Asia, yang mana aktivitas inovasi diukur melalui belanja untuk aktivitas $R \& D$, jumlah aplikasi paten yang didaftarkan ke instansi yang berwenang, serta jurnal-jurnal penelitian yang dipublikasikan secara internasional.

Hasil penelitian ini juga menemukan bahwa sebenarnya peran FDI di negara-ngera Asia lebih kepada untuk membantu negara-negara tersebut dalam memproduksi hasil-hasil dari aktivitas inovasi. Hal ini dibuktikan dari pengaruh moderasi FDI yang dapat mengubah arah pengaruh aktivitas $R \& D$ dan aktivitas paten yang semulanya negatif tanpa bantuan FDI menjadi positif dengan adanya dukungan $F D I$.

Hal ini bisa terjadi disebabkan karena meskipun negara-negara di Asia mungkin mampu menghasilkan inovasi yang bagus secara komersil, namun karena keterbatasan sumber daya yang mereka miliki, mereka tidak mampu merealisasikannya ke dalam bentuk produk segaligus memproduksinya dalam jumlah besar.

\section{Saran}

Paket investasi asing dalam bentuk FDI menjadi solusi atas semua keterbatasan sumber daya yang mereka miliki, yang membuat negara-negara tersebut mampu memproduksinya dan memasarkannya, sehingga dengan sendirinya dapat meningkatkan nilai ekspor produk-produk berteknologi tinggi pada negara-negara tersebut.

\section{DAFTAR PUSTAKA}

Adams, R. Bessant, J. and Phelps, R. (2006). "Innovation Management Measure: A review",. International Journal of Management Reviews 8(1): 21 47

Braunerhjelm, P. dan Thulin, P. (2008). Can countries create comparative advantages? R\&D expenditures, high-techexports and country size in 19 OECD countries, 19811999. International Economic Journal, 22(1), 95-111.

Chen, Yufen \& Chen, Jin. 2009. The impact of FDI on regional technological capabilities: evidence from China. Journal of Knowledge-based Innovation in China, 1(2), pp.143-158, https://doi.org/10.1108/17561410 910949391

Chih-Hai Y \& Yi-Ju H. (2009). Do Intellectual Property Rights Matter to Taiwan's Exports? A Dynamic Panel Approach. Pacific Economic Review, 14(4), Pages: 445-579.

Ekananda, M \& Parlinggoman, D.,J. (2017). The Role of High-Tech Exports and Foreign Direct Investments (FDI) on Economic Growth. European Research Studies Journal Volume, 20(4), 2017.

Gervais D. J. (2009) . (Re)implementing the Agreement on Trade-Related Aspects of Intellectual Property Rights to Foster Innovation.The Journal of World Intellectual Property. 12 (5) 348-370.

Ghazal, R \& Zulkhibri, M. (2015). Determinants of innovation outputs in developing countries: Evidence from panel data negative binomial approach. Journal of Economic Studies, 42(2),pp.237-260, 
https://doi.org/10.1108/JES-012013-0016

Hasanov, Z, Abada, O \& Aktamov, S. (2015). Impact of innovativeness of the country on export performance: evidence from Asian countries. IOSR Journal of Business and Management, 17(1), PP 33-41.

Ismail, N., W. (2013). Innovation and High-Tech Trade in Asian Countries. International Conference on Recent Developments in Asian Trade Policy and Integration, 20th and 21st February, 2013.

Kabaklarli, E., Duran, M.S. \& and Ucler, Y.T. (2017). The Determinants Of HighTechnology Exports: A Panel Data Approach For Selected Oecd Countries. DIEM, 3(1), pp. 888900. Available at: https://hrcak.srce.hr/187437 (Accessed 26 December 2018).

Kabaklarli, E., Duran, M.S. \& Ucler, Y.T. (2018). High-Technology Exports and Economic Growth: Panel Data Analysis For Selected OECD Countries. Forum Scientiae Oeconomia, 6(2)

Khachoo, Q \& Sharma, R. (2017). FDI and Incumbent R\&D Behavior: Evidence From Indian Manufacturing Sector. Journal of Economic Studies, 44(3) ,pp.380399, https://doi.org/10.1108/JES10-2015-0188

Leman E \& Ismet, G. (2015). The Effects of Foreign Direct Investment on R\&D and Innovations: Panel Data Analysis for Developing Asian Countries. Procedia - Social and Behavioral Sciences 195 ( 2015 ) 749 - 758.
Li, Z., Li, Jun \& He, B. (2018). Does foreign direct investment enhance or inhibit regional innovation efficiency?: Evidence from China. Chinese Management Studies, 12(1),pp.35-55, https://doi.org/10.1108/CMS-022017-0034

Mehrara, M., Seijani, S., Rezazadeh K, Abbas. (2017). Determinants of high-tech export in developing countries based on Bayesian model averaging. Zbornik Radova Ekonomskog Fakultet au Rijeci. 35 . 199-215.

10.18045/zbefri.2017.1.199.

Olena, I. (2010). Do Stronger Patent Rights Raise High-Tech Exports to the Developing World?. Journal of International Economics, 18(1), Pages 38-47.

Petrariu, R., Bumbac, R \& Ciobanu, R. (2013). Innovation: a path to competitiveness and economic growth. The case of CEE countries.Theoretical and Applied Economics, 20(1), pp. 15-26.

Rahman, S., Suwitho \& Purwati, A. A. (2019). Commercialization of High-Tech Innovations and Economic Growth in the Most Innovative Countries in the World. Proceedings of the IIUM International Conference on Business Management (IICBM 2019): 080-067.

Sandu, S., \& Ciocanel, B. (2014). Impact of R\&D and Innovation on High-tech Export. Procedia Economics and Finance 15 80-90.

Shukla, S. (2017). Innovation and Economic Growth: A Case Of India. Humanities \& Social Science Review, 5(2), pp 64-70. 
Weishi, G.,U, Titus O., A, \& Yan, Y. (2008). The Contribution of Foreign Direct Investment to China's Export Performance: Evidence from Disaggregated Sectors. Selected Paper prepared for presentation at the American Agricultural Economics Association Annual Meeting, Orlando, FL, July, 2008.

$\mathrm{Wu}, \quad \mathrm{Y}$. (2010). Innovation and Economic Growth in China. University of Western Australia, Perth.

Zhang, K., H. (2006). FDI and Host Countries' Exports: The Case of China. Economia Internazionale / International Economics, Camera di Commercio Industria Artigianato Agricoltura di Genova, 59(1), pages 113-127. 